\title{
Syndrome of Declining Economic Importance of Agriculture in Bihar (1960-2018)
}

\author{
Jitendra Kumar Sinha ${ }^{1, *}$, Anurodh Kumar Sinha ${ }^{2}$ \\ ${ }^{1}$ Retired Sr. Jt. Director, DES, Bihar, India. \\ ${ }^{2}$ Monitoring \&Evaluation, BRLPS (JEEViKA), India.
}

\begin{abstract}
How to cite this paper: Jitendra Kumar Sinha, Anurodh Kumar Sinha. (2022) Syndrome of Declining Economic Importance of Agriculture in Bihar (1960-2018). Journal of Humanities, Arts and Social Science, 6(1), 1-15.

DOI: $10.26855 /$ jhass.2022.01.001
\end{abstract}

Received: November 22, 2021

Accepted: December 18, 2021

Published: January 13, 2022

*Corresponding author: Jitendra Kumar Sinha, Retired Sr. Jt. Director, DES, Bihar, India.

Email: jksinha2007@rediffmail.com

\begin{abstract}
As economic development proceeds, agriculture declines as a proportion of GDP. This paper utilizes existing methodology to analyze this issue with time series data (1960-2018) for Bihar. The study focuses on changes in the GDP shares of agriculture, manufacturing and services, and considers the implications of these changes for overall economic performance. A decomposition of the total decline in the share of agriculture in GDP suggests that the relative price effects which have received the most attention in the literature were found to be relatively minor influences. Decline in the price of agricultural output relative to the price of manufactured output contributed around ten per cent of the measured decline in agriculture's share of GDP. The rise in the relative price of services contributed an additional 18 per cent. Changes in the economy's stocks of capital and labor, and a possible bias against agriculture in technical change were found to contribute over three quarters of the total decline in the share of agriculture in the Bihar economy. The importance of the capital and labor variables accounting for almost three quarters of the observed decline in the share of agriculture. Supply side influences such as capital accumulation and technical change may be the most important determinants of the decline in agriculture's share of GDP in Bihar. Demand side factors operating through relative commodity prices, seem to be much less important. This conclusion has major implications for policies for economic development and structural change, and suggests a need for reorientation of the literature on agriculture's role in economic development towards supply side influences of factor accumulation and technical change.
\end{abstract}

\section{Keywords}

Agriculture, Capital accumulation, Economic Development, GDP, Technical change

\section{Introduction}

The transformation of agriculture from the dominant sector to a small sector is a central feature of economic development. Given the ramifications of this transformation, its causes and consequences have appropriately received enormous attention in the literature. The literature has identified a number of economic forces contributing to agriculture's relative decline. They have included: (i) the effects that changes in income and population levels have on the demand for food relative to other goods and the resulting effects of these demand shifts on relative commodity prices; (ii) differences in the rates of technical change between sectors; (iii) changes in aggregate supplies of capital and labor in the economy and their resulting effects on industry structure; and (iv) the implications that adjustment costs and other impediments to factor movements have for the rates at which resource allocation will respond to the 
above determinants of agriculture's share. While the causes of the decline in the agricultural sector are not generally policy variables, most of them are subject to policy influence. Price policy for the agricultural and industrial sectors appears to have a major impact on the relative prices of these goods and, in developing countries at least (Krueger, Schiff, \& Valdes, 1988), a negative effect on agricultural output. Similarly, the level of the capital stock can be influenced by taxation and investment policies while the size of the labor force can be influenced by policies on immigration and fertility.

The rate of technical change, especially in agriculture, can be influenced by policy towards research, extension and education. Given the importance of these policy issues, information on the structural parameters which determine the effects of policy becomes a high priority. In the past, two major approaches have been used to analyze this process of structural change:

(i) cross sectional econometric studies; and

(ii) computable general equilibrium (CGE) models.

Cross sectional studies generally do not include an explicit role for price variables, and tend to be reduced-form in nature with the endogenous price variables substituted out. By contrast, relative prices play an important part in most analyses using CGE models. CGE models can provide many insights into changes in the role of the agricultural sector, and have the advantage of allowing virtually any degree of disaggregation. However, they depend upon a large number of parameters for which few direct empirical estimates are generally available unless a largescale project involving the estimation of these parameters is undertaken for the particular country. A CGE model allows a higher degree of disaggregation than would be achievable with direct estimation. However, direct estimation may be useful either as a complementary approach or as an alternative where resources to construct a CGE model are not available.

In the quantitative component of this paper, we apply a three sector modeling technique to time series data for Bihar, a low income developing state of India where the process of structural change has been proceeding slowly. In contrast with most other econometric studies of structural transformation and growth, the potential role of price changes is emphasized in this study.

A brief survey of the relevant literature is presented in the next section of the paper. Then, in Section 3, the methodology is described. The data are then discussed in Section 4. Results are presented in Section 5. Finally, we offer some tentative conclusions and proposals for future research.

\section{Agriculture in Economic Development (Low productivity and relative decline)}

Economic thought on the role of agriculture in economic development has been dominated by two empirical observations. First, as economic growth proceeds, agriculture declines in economic importance relative to manufacturing and services. Second, at any stage of this growth process, resources frequently appear to be less productive in agriculture than in industry. The two phenomena are obviously connected. Higher economic returns to mobile factors of production in industry than in agriculture (the observed productivity difference) provide the economic incentive for their movement out of agriculture during the growth process (the observed secular decline of agriculture). Economic policies toward agriculture have been influenced by the way these two phenomena have been interpreted. The decline of agriculture relative to industry has been misinterpreted to mean that industrialization causes economic growth, rather than being a manifestation of it. The lower measured productivity of labor in agriculture has also been misinterpreted to mean that forced reallocation of resources from agriculture to industry will necessarily raise national income in the short term and promote growth in the longer term-a conclusion which ignores the economic forces responsible for the long-term persistence of productivity differentials. We shall review the literature on these two phenomena in turn, taking agriculture's productivity first, followed by its relative decline.

\subsection{Agriculture as a stagnant sector}

Agriculture was earlier viewed as a backward and relatively stagnant sector whose main contribution to economic growth was to fuel the dynamic urban-based manufacturing and service sectors, particularly the former. Agriculture was seen primarily as a potential supplier of the food, labor and savings needed to promote urban led growth. This was the perspective of the many studies prompted by Lewis (1954). Lewis himself had mentioned the simultaneous role of agricultural and industrial development but his emphasis was on the latter and this was even more true of the influential dual economy models which followed, especially Pei and Ranis (1964). Lewis analysis of 
"surplus labor" in agriculture reinforced this view: workers could be relocated from agriculture to industry without loss of agricultural output. The source of Lewis supposed surplus labor was not, as Jorgenson (1961) and Schultz (1964) assumed in their criticisms of Lewis, zero marginal productivity of labor in agricultural production, but the willingness of rural households to supply additional labor at constant, but positive, supply price (Sen, 1966; Lewis, 1972). The impression remained that there was little to be lost from policies aimed at draining the agricultural sector of resources which could be used more productively elsewhere. The import substitution-led recommendations of Prebisch (1950) and others also stressed the importance of manufacturing. Development required the transfer of resources from stagnant agriculture to dynamic manufacturing. Government policy should promote this process by protecting manufacturing in the early stages of industrialization. High tariff barriers against imported manufactured goods were seen as an appropriate way of achieving this end.

\subsection{Agriculture as a Declining Sector}

The empirical fact of agriculture's decline during economic growth is well known. Demand-side factors are its best understood causes. First, consider a closed economy. As income rises per head of population, at given commodity prices expenditure shifts towards services and manufactured goods relative to food, the phenomenon known as Engel's Law (Schultz, 1953). If all sectors expanded output at the same rate, excess supply of food would result. The mechanism by which demand shifts affect industry outputs is thus changes in relative commodity prices. This same mechanism operates at a global level.

Low expenditure elasticities of demand for food relative to other traded goods can be expected to result in declining international prices of food relative to other traded goods over time (World Bank, 1982). For an individual trading country, this analysis changes but only slightly. For given rates of domestic trade taxes and subsidies, international prices determine the relative domestic prices of traded goods such as food and manufactures. For a regional state like Bihar, these relative traded goods' prices are independent of domestic demand conditions, but the level of these prices relative to those of non-traded goods, such as services are affected by domestic demand. Services typically have expenditure elasticity of demand greater than unity (Anderson, 1988), implying that the aggregate of all other goods, i.e., traded goods-has an expenditure elasticity below unity. This reasoning is thus consistent with the observed decline of traded goods prices relative to non-traded goods as economies develop (Kravis \& Lipsey, 1988; Falvey \& Gemmell, 1989). In summary, as incomes rise the demand side forces will lead to a decline in agricultural product prices relative to prices in general. Falling agricultural prices relative to other goods will reduce agriculture's share of GDP in two ways. First, provided GDP is measured at current prices, even if industry output levels were constant, agriculture's measured share of GDP would fall. Second, role of agriculture was emphasized in simultaneous development of agriculture and industry. Johnston and Mellor listed five roles for agriculture in the development process:

(1) increase the supply of food for domestic consumption;

(2) release labor required for the industrial sector;

(3) increase the size of the market for domestic manufactured goods;

(4) release domestic savings for investment in industry; and

(5) earn foreign exchange.

As Myint (1975) pointed out, the domestic interdependence stressed by the first four roles reflects a closed economy perspective. Only the fifth, foreign exchange earnings, reflects the role of international trade. This in turn reflects the influence of the Indian model - in which the domestic economy is so great as to minimize the relative importance of foreign trade. The "Green Revolution" experiences of the late 1960s onwards it has no longer been possible to characterize agriculture as being inherently stagnant. Experience has shown that when profitable opportunities exist, even illiterate farmers will innovate, confirming the earlier thesis of Schultz (1964). The importance of public investment in agricultural technology and infrastructure has now been recognized in the economic development literature and although urban bias remains a central characteristic of the policies of most low countries. Despite this, the view persists in popular thinking that agriculture is an inherent backward corner of the economy whose main role in development is as a reservoir of underemployed resources usable for urban-based development. Reynolds (1975) distinguishes between static and dynamic interpretations of agriculture as a 'resource reservoir'. The 'static' view coincides with the simple dual economy models described above.

It is through appropriate public policies that a stagnant agricultural sector may be squeezed of resources-food, labor and savings without significant cost in terms of agricultural output but with substantial benefit in terms of industrial output. The dynamic view, which roughly characterizes the present state of thought, is that in an economy where agricultural output is rising as a consequence of technical change and investment, part of the increment in 
farm output and income is available for transfer to non-agriculture' (Reynolds1975) response to the relative price changes, resources will move away from agriculture towards other sectors where the returns are greater.

Differences in rates of technical change between sectors will also contribute to changes in the composition of GDP. If, as is widely thought, the rate of technical change is relatively slow in agriculture for developing countries (Chenery \& Syrquin, 1986), then this would directly contribute to a decline in the share of agriculture in the economy. Another possible influence on the size of the agricultural sector is changes in the total supply of labor and capital in the economy. If the factor intensities of the agricultural sector and other sectors differ, then Rybczynski's theorem (Rybczynski, 1955) would lead us to expect that changes in factor supplies will induce changes in the output mix. In particular, if agriculture is more labor intensive than the rest of the economy, then capital accumulation will cause agriculture's output to fall absolutely.

\section{Methodology}

The major determinants of the size of the agricultural sector identified in Section 2 were: output prices, factor endowments, and technical change. The approach used in this study is based on time series data for Bihar. Time series data are required to capture the dynamics of adjustment resulting from factors such as adjustment costs, information and implementation lags. Since the major focus of interest is in the long-run structural parameters, an approach which readily allows these parameters to be estimated was required. Development of the methodology for the study required consideration of both the long-run structure and of the dynamic specifications and behavioral properties of the data.

\subsection{Long run structure}

The analysis considers three major sectors-agriculture, manufacturing and services; utilizing capital, labor and a changing level of technical knowledge. This technology can be characterized by the implicit function:

$$
\mathrm{H}(\mathrm{A}, \mathrm{M}, \mathrm{S}, \mathrm{K}, \mathrm{L}, \mathrm{T})=0
$$

where: $\mathrm{A}$ is agricultural output; $\mathrm{M}$ is manufacturing output; $\mathrm{S}$ is services output; $\mathrm{K}$ is the capital input; $\mathrm{L}$ is the labor input; and $\mathrm{T}$ is an index of technology. Given the focus of interest in this study, the sectoral output variables must be treated as endogenous. By contrast, the input variables can be treated as exogenous to the economy, or at least predetermined for statistical purposes.

\subsection{Dynamics}

The system of transformed dynamic equations used in the analysis can be derived from a general reduced form equation system:

$$
\mathbf{Y}_{\mathbf{t}}=\sum \boldsymbol{Y}_{t-i} C i+\sum \boldsymbol{X}_{t-i} \boldsymbol{D}_{\boldsymbol{i}}+\mathbf{U}_{\mathbf{t}}
$$

where: $Y_{t}$ is a vector of endogenous variables; $X_{t}$ is a vector of exogenous variables; and $U_{t}$ is a vector of disturbances. $\mathrm{C}_{\mathrm{i}}, \mathrm{D}_{\mathrm{i}}$ are the set of related parameters.

The matrix of long run multipliers for equation (2) is $\Omega=\left(\sum \mathrm{B}_{\mathrm{i}}\right)\left(\mathrm{I}-\sum \mathrm{C}_{\mathrm{i}}\right)^{-1}$

To estimate the matrix of long run multipliers directly, we added $\mathrm{D}_{\mathrm{i}} \mathrm{X}_{\mathrm{t}}$ to the $\mathrm{X}_{\mathrm{t}}$ term on the right hand side of (2), maintaining the equality by adding $-\mathrm{D}_{\mathrm{i}} \mathrm{X}_{\mathrm{t}}$ to each of the $X_{t-I}$ terms on the right hand side. Subtracting $\mathrm{C}_{\mathrm{i}} \mathrm{X}_{\mathrm{t}}$ from both sides of (2) similarly leaves the equality undisturbed.

The matrix of long run coefficients can then be obtained directly by estimating the following system of equations:

$$
\mathrm{Y}_{\mathrm{t}}=\sum \beta i \mathrm{Y}_{\mathrm{t}} F_{i}+X_{t} \Omega,+\sum \beta i X_{t} G_{i}+V_{t}
$$

where $F_{i}=C_{i} H, \mathrm{G}_{\mathrm{i}}=-\mathrm{D}_{\mathrm{i}} \mathrm{H}, \mathrm{V}_{\mathrm{t}}=\mathrm{U}_{\mathrm{t}} \mathrm{H}$; and $\mathrm{H}=\left(\mathrm{I}-\sum \mathrm{Ci}\right)^{-1}$

Because current endogenous variables appear on the right hand side of the equation system (3), a simultaneous equation estimator such as Three Stage Least Squares (3SLS) or Full Information Maximum Likelihood (FIML) is required. Direct estimation of the long run parameters in this way has two major advantages. Firstly, the fact that it provides direct estimates of both the long-run coefficients and their standard errors is substantially more convenient than solving for these values after estimation. Secondly, it becomes straightforward to impose and test the restrictions implied by economic theory (particularly homogeneity and symmetry) on the long run estimates. The estimation method used is a relatively simple, linear-in-variables and linear-in-coefficients approach to estimation of the long-run coefficients, together with the dynamics of interest. The simultaneous estimation of the long-run coeffi- 
cients and the dynamics should help to improve the quality of the long-run estimates, by overcoming omitted variable bias. Since the dynamic specification can be interpreted in terms of adjustment costs and lags, it has an economic interpretation, as well as playing an important statistical function by improving the specification of the model.

\section{Data Sources}

Primary and secondary data sources were used in this analysis. Data available from the Directorate of Economics and Statistics, Bihar and other relevant Government Departments were used for the basic primary data while relevant research documents were utilized to gather necessary secondary data for the period 1960-2018.

Obtaining the variables actually used in the econometric analysis required some transformation of the available data. For each sector identified in the data set, an implicit price deflator was calculated by dividing the current price estimate of the value of output (in value added terms to avoid double counting) by the constant price estimate of output.

The capital stock variable in the analysis was estimated using the Summers and Heston data series on investment at constant prices beginning in 1950. A capital stock series was first calculated using the recursive relationship:

$$
\mathrm{K}_{\mathrm{t}}=(\mathrm{l}-\mathrm{h}) \cdot \mathrm{K}_{\mathrm{t}-1}+\mathrm{I}_{\mathrm{t}}
$$

where: $K_{t}$ is the capital stock at the end of each period, $h$ is the depreciation rate and $I_{t}$ is a constant-price measure of the quantity of investment in each period. A value of 0.03 was chosen for h based on estimates. Sensitivity analysis of the responsiveness of the results to this estimate was undertaken over a range from 0.035 to 0.06 , but the results were not found to be sensitive to this parameter over this range. Estimating the capital stock series using equation (4) requires an estimate of the unknown opening capital stock in the initial period. The estimate was obtained by first regressing the log of investment against time for the period 1950-60 to obtain an average growth rate and a trend value for investment in1949, designated Io. Assuming the capital stock was in steady state equilibrium at that time allowed the opening capital stock to be estimated as:

$$
\mathrm{K}_{\mathrm{o}}=I o /(g+\mathrm{h})
$$

where $\mathrm{K}_{\mathrm{o}}$ is the opening capital stock in 1950; $\mathrm{g}$ is the estimated growth rate of real investment (and also of capital in the steady state); and $\mathrm{h}$ is the rate of depreciation. Since the capital stock series was estimated recursively over the entire period from 1950, any errors resulting from mis-estimation of the initial period capital stock would be unlikely to be very important.

\section{Estimation and Results}

Econometric results obtained using time series data appear to be influenced by the time series behavior of the data as well as the nature of the relationship between the variables of interest. Thus, both the data and the individual equations were examined prior to analysis of the system.

\subsection{Behavior of the Data}

The Bihar economy grew relatively slowly over the period, with an average growth rate of real GDP of 2.9 per cent, and hence the pressures for structural change would be expected to be relatively intense in this economy. The discussion in the literature on structural transformation has identified three major sectors whose behavior needs to be considered: agriculture; manufacturing; and services. The shares of agriculture, manufacturing, services and mining in the Bihar economy indicate the decline in the share of agricultural sector, from over 51 per cent in 1960 to around 18 per cent in 2018. On average, the share of the agricultural sector declined by almost 0.3 per cent per year. By contrast, the share of the services sector grew from 27 per cent to around 62 per cent, an average increase of 0.4 per cent per year. The manufacturing share has risen, from a relatively small base, at 0.1 percent per year. The share of the mining sector has remained relatively small throughout the period. Changes in the volume of output, are considerably less volatile than the corresponding value measures and their behavior appears to be dominated by relatively steady trends. The average rate of growth of output in the manufacturing sector, at 0.5 per cent per year, while services output grew at 2.3 percent. Agricultural output grew at an average rate of 0.3 per cent per year.

Over the period as a whole, total prices of agricultural and manufactured goods trended down, while the price of services appears to have trended up. On average, the agricultural price index fell 0.4 per cent per year relative to the manufactures price index. By contrast, the price index for services rose by an average of 0.6 per cent per year relative to the price of manufactures. In contrast with the price indexes, the indexes of the capital stock and of popula- 
tion have increased relatively smoothly. The estimated real capital stock grew considerably faster than the rate of growth of population, with the capital stock growing at an average rate of 0.4 per cent per year while population grew at 1.6 percent. All of the series trended up or down for sustained periods. For some of the series, such as population and the capital stock, these trends were not subject to major changes while for others, the trend varied markedly. The price series, in particular, did not appear to trend smoothly, but rather appeared to 'drift', with persistent deviations from any underlying trend level of prices. This behavior can have major implications for inferences based on econometric analysis and hence requires further consideration.

For a time series variable to drift in its level form, but to have a constant mean when differenced once implies that an auto regression of the current value of the series on its lagged value has a unit coefficient. The simplest model for which this applies is the random walk model:

$$
\mathrm{Z}_{\mathrm{t}}=1 . \mathrm{Z}_{\mathrm{t}-1}+\mathrm{e}_{\mathrm{t}}
$$

where: $\mathrm{Z}_{\mathrm{t}}$ is a time series variable and $\mathrm{e}_{\mathrm{t}}$ is a random error term.

The Dickey-Fuller test for which critical values are provided in Fuller (1976) provides a relatively simple and straight forward test for integration based on a regression in the form of equation (6). For convenience, $\mathrm{Z}_{\mathrm{t}-\mathrm{I}}$ may also be subtracted from both sides of (6) making the test statistic the usual $t$ value of the coefficient $b$ on $\mathrm{Z}_{\mathrm{t}-1}$ in the regression:

$$
\left(\mathrm{Z}_{\mathrm{t}}-\mathrm{Z}_{\mathrm{t}-1}\right)=\mathrm{b} . \mathrm{Z}_{\mathrm{t}-1}+\mathrm{e}_{\mathrm{t}}
$$

For higher order time series processes, this estimating equation may be augmented with additional lagged differences of $Z_{t}$ to obtain uncorrelated residuals.

Assessing whether two or more non-stationary time series variables are co-integrated involves analyzing whether the residuals from the co-integrating regressions are stationary. The Durbin-Watson statistic for the co-integrating regression provides one possible indication of non-stationary. Very low values of the Durbin-Watson statistic, as in the case of spurious' regression are an indication that the data series are not co-integrated. Engle and Granger (1987) suggest applying the Augmented Dickey-Fuller test to the residuals of the co-integrating equation. The methodology adopted in this paper involved first testing the integration properties of the individual series used in the analysis. If all or most of the series were found to be integrated, then attention would be focused on the co-integration properties of the estimating regressions. If the dependent variables, but not the regressors, were found to be integrated, then attention be given to transforming the regress ands to achieve non-stationary. If all variables were found to be non-stationary, then standard regression theory would be applicable. The transformed regression model used is appropriate both for regressions on stationary data and for co-integrating regressions on non-stationary data and so only the interpretation of the results is affected in these cases. The results of the Dickey-Fuller and Augmented Dickey-Fuller tests for the variables appearing in the analysis are presented in Table 1.

\begin{tabular}{|c|c|c|c|}
\hline & DF & $\mathrm{ADF}$ & Interpretation \\
\hline \multirow{2}{*}{ LPA } & -0.22 & 0.03 & \multirow{2}{*}{ Integrated } \\
\hline & $(-1.55)$ & $(0.20)$ & \\
\hline \multirow{2}{*}{ LPS } & -0.10 & 0.07 & \multirow{2}{*}{ Integrated } \\
\hline & $(-0.93)$ & $(0.79)$ & \\
\hline \multirow{2}{*}{ LCAP } & -0.02 & -0.02 & \multirow{2}{*}{ Not integrated } \\
\hline & $(-4.4)$ & $(-4.6)$ & \\
\hline \multirow{2}{*}{ LLAB } & -0.02 & -0.02 & \multirow{2}{*}{ Not integrated } \\
\hline & $(-14.3)$ & $(-14.9)$ & \\
\hline \multirow{2}{*}{ SA } & -0.008 & 0.04 & \multirow{2}{*}{ Integrated } \\
\hline & $(-0.12)$ & $(0.79)$ & \\
\hline \multirow{2}{*}{ SS } & 0.01 & 0.11 & \multirow{2}{*}{ Integrated } \\
\hline & $(0.13)$ & (1.4) & \\
\hline
\end{tabular}

Table 1. Dickey-Fuller and Augmented Dickey-Fuller tests for variables used in the analysis

Notes: LPA $=$ Log of the price of agricultural output deflated by the price of manufactures; LPS =Log of the price of services deflated by the price of manufactures; $\mathrm{LCAP}=\mathrm{Log}$ of the beginning of period capital stock; LLAB= Log of the population; SA = Value share of agriculture in non-mining GDP; SS= Share of services in non-mining GDP. Critical values: DF Test: -3.0 at 5 per cent, -2.63 at 10 per cent; ADF Test approximately -2.8. 
Table 2. Single equation estimates of the translog share equations ${ }^{\mathrm{a}}$

\begin{tabular}{|c|c|c|c|c|c|}
\hline \multirow{2}{*}{ Parameter } & \multicolumn{2}{|c|}{ OLS } & \multicolumn{3}{|c|}{$2 \mathrm{SLS}^{\mathrm{b}}$} \\
\hline & SA & SS & SA & SS & $\mathrm{SA}^{\mathrm{c}}$ \\
\hline \multirow[t]{2}{*}{ Constant } & -3.9 & 5.54 & 5.10 & 5.24 & -2.15 \\
\hline & $(-1.11)$ & $(-1.57)$ & $(-1.08)$ & $(1.07)$ & $(-1.00)$ \\
\hline \multirow[t]{2}{*}{ LPA } & 0.20 & -0.20 & 0.21 & -0.22 & 0.22 \\
\hline & $(11.6)$ & $(-11.6)$ & $(9.56)$ & $(9.60)$ & $(11.1)$ \\
\hline \multirow[t]{2}{*}{ LPS } & -0.17 & 0.29 & 0.17 & 0.21 & -0.18 \\
\hline & $(-3.20)$ & $(5.40)$ & $(-3.09)$ & $(5.06)$ & $(-3.47)$ \\
\hline \multirow[t]{2}{*}{ LCAP } & -0.20 & 0.21 & 0.23 & 0.22 & -0.19 \\
\hline & $(-2.6)$ & $(2.65)$ & $(-2.47)$ & $(2.24)$ & $(-2.66)$ \\
\hline \multirow[t]{2}{*}{ LLAB } & 0.62 & 0.69 & 0.76 & -0.68 & 0.43 \\
\hline & $(1.49)$ & $(-1.69)$ & $(1.40)$ & $(-1.21)$ & $(1.57)$ \\
\hline \multirow[t]{2}{*}{$\mathrm{T}$} & 0.003 & 0.001 & 0.004 & -0.0004 & \\
\hline & $(-0.78)$ & $(0.22)$ & $(-0.70)$ & $(-0.07)$ & \\
\hline $\mathrm{R}^{2}$ & 0.98 & 0.96 & 0.98 & 0.96 & 0.98 \\
\hline DW & 2.21 & 1.69 & & & \\
\hline \multicolumn{6}{|l|}{ Diagonostics $^{\mathrm{d}}$} \\
\hline Bera-Jarque & 1.14 & 5.58 & & & \\
\hline RESET(2) & 4.31 & 0.39 & & & \\
\hline B.P. Hetero & 0.69 & 0.43 & & & \\
\hline \multicolumn{6}{|l|}{ LM } \\
\hline-1 & -0.67 & 0.75 & & & \\
\hline-2 & 0.59 & 0.41 & & & \\
\hline \multirow{2}{*}{ DF } & -1.13 & -0.85 & & & \\
\hline & $(-5.46)$ & $(-4.13)$ & & & \\
\hline \multirow{2}{*}{$\mathrm{ADF}$} & -1.03 & -0.80 & & & \\
\hline & $(-3.12)$ & $(-2.83)$ & & & \\
\hline
\end{tabular}

${ }^{\mathrm{a}}$ Figures in parentheses are t-statistics.

blnstruments list for 2SLS; LPS; LCAP; LLAB; LPA $\mathrm{t}_{\mathrm{t}-1}$; T; $\mathrm{LKA}_{\mathrm{t}-1} ; \mathrm{LKS}_{\mathrm{t}-1}$; LCAP; LLAB $\mathrm{LA}_{\mathrm{t}-1}$ where LKA $\mathrm{t}_{\mathrm{t}-1}$ is the quantity of output in period t-1 and LKS is the corresponding quantity variable for services. All other variables are as defined in Table 1.

${ }^{\mathrm{c} E x c 1 u d i n g}$ the time trend variable.

${ }^{\mathrm{d}} \mathrm{DW}$ is the Durbin-Watson statistic. The Bera-Jarque test for normality of residuals is distributed as a Chi-Squared with $2 d f$ (Critical value at 5 per cent $=5.99)$. The RESET(2) testis distributed as F(l, 19), with a critical value of 8.18 at the 5 per cent significance level. The Breusch-Pagan test for heteroscedasticity is distributed as a Chi-Squared with $1 \mathrm{~d} \mathrm{f}$ and a critical value of 3.84 at a 5 per cent significance level. The LM t-statistics test for residual autocorrelation at each order of lag. The critical value for the D.F test for co-integration is -3.0at 5 per cent.

The results presented in Table 1 are generally consistent with the impression created by inspection of the data that most of the data series 'drift', with shocks to the series affecting all of their future values. The share variables which form the dependent variables in the translog estimating equations each appear to have a root close to unity. While deflating the prices of agricultural and service sector output by the price of manufactured output removes the common nominal trends, it is not sufficient to make the resulting series stationary. Thus, the price series, as well as the dependent variables, appear to be non-stationary in this case.

The formal hypothesis of a unit root is decisively rejected for both the capital and labor variables. This could present problems given the apparent non stationary of the dependent variables since a stable long-run relationship cannot exist between a stationary and a no nstationary variable (Engle \& Granger, 1987). In this case, however, the problem may lie more with the nature of the formal test than with the behavior of the time series. By the nature of these series, a shock in one period persists for a very long time. This is consistent with the very small estimated coefficients obtained in the test. In practice, it seems likely that these variables will behave like integrated series. The relationship between the variables was therefore investigated using the procedures discussed in Section 2. With the economy divided into three sectors, there are only two independent share equations to be estimated. The two equations estimated in this study were the agriculture and the services equations. Two sets of single equation estimate of the relevant equations are presented in Table 2. The first pair of equations was estimated by ordinary least 
squares (OLS), while the second group of three was estimated using a two-stage least squares estimator. The OLS equations allow an initial exploration of the properties of the relationship between the variables and enable diagnostic tests on the regression residuals to be performed to ensure that the major underlying assumptions of the regression approach are not violated. The OLS estimates are of particular interest given the apparently non-stationary nature of the variables being analyzed. They allow simple tests for the existence of a stable long-run relationship between the variables (i.e. whether they are co-integrated) to be performed. Further if such a stable long-run relationship is found to exist, the estimators are known to converge relatively rapidly and hence the OLS estimates may provide a reasonably good indication of the long-run relationship despite the omission of relevant dynamic variables. The OLS regression for the share of agriculture in total output (SA) presented in Table 2 yields coefficient estimates whose signs are consistent with expectations. As expected, the price of agricultural output has a positive impact on the value share of agriculture in non-mining output. Similarly, the price of services has a negative impact on agriculture's share. Consistent with the Rybczynski effect an increase in the stock of capital has a large negative effect on agriculture's share. Also as expected, an increase in the supply of labor would be expected to raise the share of agriculture in the economy. The coefficient on the time trend variable used as a proxy for the effects of technical change is negative, consistent with relatively slow technical change in agriculture, although this coefficient is not statistically significant.

The coefficient in the SS equation is also of interest. The positive coefficient on LPS and the negative coefficient on LPA are as expected. However, the positive coefficient on the capital variable and the negative coefficient on the labor variable are somewhat surprising. In terms of the Rybczynski effect, these result would be consistent with the service sector being relatively capital intensive. This result may, however, not be unreasonable given the inclusion of some relatively capital intensive industries in this aggregate. With subsectors such as electricity and transport infrastructure included in this sector, and the relatively heavy capital investment required for industries such as tourism, these results may well be reasonable. Technological change in services appears to occur at a similar rate to the weighted average of and manufacturing.

A range of diagnostic tests was performed on the residuals of the OLS regressions, and the result of some of the major tests performed is reported in Table 2. None of these test results provide statistical grounds to question the adequacy of the model. Even though indication of auto-correlation due to omitted dynamics would be acceptable, and even expected, given the simple, static nature of the specification, the test results provide virtually no indication of residual auto-correlation. The RESET tests for functional form and the Breusch-Pagan test for heteroscedasticity are particularly important since the problems would not be alleviated by the inclusion of additional dynamics. Neither of these tests provides cause for concern.

The final two tests in Table 2 are the Dickey-Fuller (DF) and Augmented Dickey-Fuller (ADF) tests for co integration. When applied to the residuals of a potentially co-integrating regression, these tests provide an indication of whether a stable long relationship exists between variables were themselves no nstationary. In this case, both the $\mathrm{DF}$ test and the ADF test led to the conclusion that there is co-integration between the shares of agriculture and services, and the explanatory variables hypothesed to determine them. One concern with the use of OLS to estimate the relationships of interest is the use of the current price of agricultural output as an explanatory variable. Given the production lags in agriculture, many major management decisions such as land preparation and planting must be made based on expectations about future agricultural prices, rather than knowledge of actual prices. As is the case when decisions are based on expected rather than actual output (Martin, 1984), this leads to an errors-in-variables problem. The variable observed, actual output price, can be viewed as a proxy variable for the relevant variable, the expectation about price held at time $\mathrm{t}-1$. Such an errors in-variables problem can be expected to lead to a downward bias in the estimated coefficient. Relatively straight forward approach to dealing with an errors in-various problem is to replace the variable observed with an error with an instrument correlated with the relevant unmeasured variable, but uncorrelated with the measurement error. In this case, since the relevant expectation is formed at time t-1, it seems appropriate to replace the actual agricultural price variable with an instrumental variable formed using information available in time t-1. In the estimation of the 2SIS estimates reported in Table 2, the actual value of LPA was replaced by an instrument formed using the lagged price and quantity variables, and the relatively predictable capital and labor variables. A Wu-Hausman exogeneity test for statistically significant differences between the OLS and 2SLSestimators was performed by augmenting the OLS equation with the residuals from the first stage regression of the 2SLS procedure. This variable was significant at the 10 percent level in the SA equation and at the 5 per cent level in the SS equation. As can be seen from Table 2 the coefficients in the 2SLSequations are, in most cases, very similar to those in the OLS equations. However, the coefficient on LPA is 
noticeably larger in the 2SLS equations. The coefficients on both the labor and capital variables also increase in absolute value in the agricultural share equation. Further examination of the results in Table 2, however, reveals a major concern with their economic interpretation. Some of the key elasticity of output with respect to price do not satisfy the requirements of economic theory at all points in the sample. To illustrate this problem, the estimated elasticities of agricultural output with respect to price obtained from the 2SLS equations are presented in Table 3 for selected points in the sample.

A necessary condition for a translog profit or revenue function to be consistent with economic theory is that it be convex with respect to output prices. A necessary (but not sufficient) condition for convexity relevant in a single equation context is that the elasticities of output with respect to own-price be positive. As can be seen from Table 3, this condition is not satisfied at all points in the sample and is only marginally satisfied at the sample means. It was thought likely that the low estimated elasticity of agricultural output with respect to its own price may have been due the use of the less efficient single-equation approach to estimation.

Accordingly, the two independent share equations in the system were next estimated as an interdependent static system. Finally, the system was estimated when augmented with first order dynamics to account for the major adjustment costs and delays in structural transformation. The results obtained from the estimation of these two equation systems are presented in Table 4.

The prefix D designates the first difference of the relevant variable.

The systems of interdependent equations reported in Table 4 were first estimated without imposing the restriction that the matrix of coefficient on the output prices be symmetric so as to allow testing of this hypothesis. The unrestricted estimates of the cross price effects were similar in magnitude and the Wald Chi-squared statistic (with 1degree of freedom) for this restriction was only 0.6 in the static model and 0.1 in the dynamic model. Thus, the restriction was imposed in estimating the systems reported in Table 4.

Unfortunately, the systems approach to estimation did not appear to overcome the problems identified in the original single-equation estimates. In general the results from estimation of the static Seemingly-Unrelated-Regression were similar to those obtained using the single equation approaches. One unexpected consequence of the systems estimation, however was a decline in the estimated own-price coefficient in the share equation for agriculture.

Table 3. Elasticities of agricultural output with respect to price

\begin{tabular}{|c|c|c|c|}
\hline Year & Agriculture & Services & Manufacturing \\
\hline \multicolumn{4}{|c|}{ A. From equation including technical change bias } \\
\hline 1960 & -0.06 & 0.03 & 0.03 \\
\hline 1970 & -0.05 & 0.02 & 0.03 \\
\hline 1980 & 0.03 & -0.04 & 0.01 \\
\hline 1990 & 0.00 & 0.05 & -0.05 \\
\hline 2000 & 0.07 & 0.01 & 0.03 \\
\hline 2010 & 0.05 & 0.02 & 0.01 \\
\hline 2018 & 0.40 & 0.38 & -0.02 \\
\hline Sample mean & 0.01 & 0.04 & 0.03 \\
\hline \multicolumn{4}{|c|}{ B. From equation excluding bias of technical change } \\
\hline 1960 & -0.04 & 0.01 & 0.03 \\
\hline 1970 & 0.03 & -0.01 & 0.04 \\
\hline 1980 & 0.06 & -0.09 & 0.03 \\
\hline 1990 & 0.03 & -0.09 & 0.06 \\
\hline 2000 & 0.09 & -0.15 & 0.06 \\
\hline 2010 & 0.36 & -0.20 & 0.05 \\
\hline 2018 & 0.48 & -0.46 & 0.02 \\
\hline Sample mean & 0.04 & 0.09 & 0.05 \\
\hline
\end{tabular}


Table 4. Estimates of the static and dynamic systems subject to the symmetry constraint

\begin{tabular}{ccccc}
\hline Parameter & SA & SS & SA & SS \\
\hline \multirow{2}{*}{ Constant } & -4.03 & 5.65 & -8.18 & 14.06 \\
& $(-1.15)$ & $(1.62)$ & $(-2.04)$ & $(3.05)$ \\
LPA & 0.20 & -0.20 & 0.185 & -0.18 \\
& $(11.8)$ & $(-12.02)$ & $(10.4)$ & $(-9.02)$ \\
LPS & -0.20 & 0.31 & -0.18 & 0.27 \\
& $(-12.0)$ & $(9.56)$ & $(-9.0)$ & $(5.14)$ \\
LCAP & -0.21 & 0.21 & -0.25 & 0.29 \\
& $(-2.8)$ & $(2.82)$ & $(-3.82)$ & $(3.68)$ \\
LLAB & 0.64 & -0.72 & 1.09 & -1.63 \\
& $(1.55)$ & $(-1.76)$ & $(2.40)$ & $(3.17)$ \\
T & -0.003 & 0.006 & -0.01 & 0.02 \\
& $(-0.70)$ & $(0.13)$ & $(-1.59)$ & $(2.19)$ \\
DLPA & & & -0.07 & 0.06 \\
& & & $(-2.20)$ & $(1.56)$ \\
OLPS & & & -0.08 \\
& & & 0.17 & $(-0.57)$ \\
OLCAP & & & -0.01 & 0.06 \\
& & & $(-0.27)$ & $(0.32)$ \\
OLLAB & & -1.31 & 4.73 \\
& & & $-0.84)$ & $(2.62)$ \\
OSA & & -0.22 & -0.26 \\
DSS & & $(-0.36)$ & $-0.36)$ \\
& & -0.63 & $(-0.19)$ \\
\hline
\end{tabular}

The results of the general first order dynamic model presented in Table 5 were of particular interest given the failure of the static system to satisfy the convexity condition. As was discussed in Section 3, estimation of the dynamic system leads to coefficients on the current explanatory variables which can be interpreted as long-run coefficients. Given this, it was expected that the coefficients obtained in this model would be larger in absolute value than those obtained using the static model. Unfortunately, as is evident from the coefficients in Table 4, this was not the case for the price coefficients. The failure of the systems estimates to satisfy the convexity condition in prices is unfortunate since it leaves us unable to satisfactorily achieve one of our major objectives in this paper to measure the extent to which adjustment costs reflected till the dynamic model reduce the level of GDP, and hence create the impression that efficiency gains would be attainable by transferring resources out of agriculture. Any such gains would, of course, be illusory since adjustment costs are as real as any other costs and should be taken into account in the efficient allocation of resources over time. Given the desirability of obtaining estimates of the complete GDP function, considerable effort was devoted to understanding the reason for its failure and to identifying alternative specifications which might better represent behavior. One potential concern with the use of the dynamic translog model is the somewhat ad hoc nature of the economic basis for the adjustment process. Quadratic adjustment costs of the type underlying ECM models Nickell (1985) or the dynamic model used in this study, have a clear interpretation for adjustment of quantities but their meaning is less clear for adjustment of shares. To examine whether this somewhat ad hoc dynamic specification caused the observed problems, a direct log-linear specification based on the solution of the first order conditions for profit maximization subject to equation (1) was investigated. Following Fisher (1979), the theoretical restrictions of homogeneity and symmetry were tested and imposed and, in addition, convexity of the matrix of output price elasticities was imposed at the sample means using the decomposition suggested by Lau (1978). Unfortunately, these specifications also failed to provide satisfactory statistical estimates.

The failure of the estimated models to satisfy the restrictions imposed by economic theory might be due to a 
number of factors. As Peterson (1979) has observed, estimation of price elasticity from time series data rarely leads to estimates of the own-price elasticity for agricultural output above 0.15 , while he obtained estimates ranging from 1.25 to 1.66 using cross-sectional data. In this context, the difficulties experienced in the use of aggregate systems approaches in this study are symptomatic of the generally problematic process of obtaining aggregate long-run price elasticities from time series data.

Given the failure of the systems estimators to satisfy the convexity condition, further attention was given to the single equation 2SLS estimates which at least satisfy the necessary condition of a positive own-price elasticity at the sample mean and at most points in the sample. These equations allow a simple decomposition of changes in the share of agriculture in the economy in response to the major determinants identified in the literature: changes in relative prices, changes in relative factor endowments, and biases in technical change. The results of two such decompositions are presented in Table 5.

Table 5. Sources of change in the share of agriculture in GDP

\begin{tabular}{ccc}
\hline & $\begin{array}{c}\text { Contribution } \\
\text { Including Tech. bias }\end{array}$ & Excluding Tech . bias $^{\mathrm{b}}$ \\
\hline Contributions of & & 10 \\
DLPA & 10 & 18 \\
DLPS & 17 & 28 \\
Total price effect & 27 & 194 \\
DLCAP & 245 & -122 \\
DLLAB & -221 & 72 \\
Total factor effect & 24 & -- \\
Technology & & 100 \\
Total & 49 & 100 \\
\hline
\end{tabular}

${ }^{\mathrm{a}}$ From equation including $\mathrm{T}$ in column 3 of Table 2.

${ }^{\mathrm{b}}$ From equation excluding $\mathrm{T}$ in column 5 of Table 2.

The first column of Table 5 is based on the result of the complete static 2SLS equation including the relative price variables (LPA and LPS), the relative factor endowments (LCAP and LLAB) and a time trend as a proxy for technological advance. Because the time trend is not statistically significant, a second set of estimates is presented based on the 2SLS equation with this variable set to zero.

From the results in the first column of Table 5, all three of the hypothesized factors have an important influence on the share of agriculture in GDP. The average decline in the share of agriculture in the economy was just under 0.9 per cent per year over the sample period. Based on the estimates from the full equation, approximately 10 per cent of this decline was due to the measured fall in the price of agricultural output relative to the price of manufactured output. Another 17 per cent was due to the increase in the relative price of services. Given the very low output price elasticity implied by this equation, these relative price effects are largely due to valuation effects rather than to output effects. If the output price elasticity were higher, the effects of price on the value shares would obviously be higher, although this effect would not be greatly affected by an own price elasticity in the 0.15 range which Peterson (1979) argues is typical for time series regression. From both sets of results presented in Table 5, the observed changes in the capital and labor endowments would each, alone, have had an enormous effect on the share of agriculture. In the model including the technological change proxy, the net effect of the relatively rapid increase in the stock of capital relative to labor was estimated to have caused 24 per cent of the observed reduction in the share of agriculture. This effect is consistent with the predictions of the Rybczoski theorem which predicts that, other things being equal, both the share of, and the absolute size of, the labor intensive sector will decline when the stock of capital is increased.

Using the equation excluding the statistically insignificant time trend, the contribution of the price effects changes very little. While the own price elasticity rises slightly, this effect is insufficient to greatly change the measured contribution of relative price changes to the share of output. In the absence of a separate variable for bias 
in technical change, the variables representing the Rybczynski effect assume much greater importance. Using this equation, the rapid accumulation of capital relative to labor accounts for 72 per cent of the estimated decline in agriculture's share.

Given the apparent importance of changes in factor proportions for the structure of the economy, and the marked variations in the rate of capital accumulation by level of economic development noted by Dowrick and Gemmell (1989), the effect of this phenomenon on the structure of the economy would appear to warrant greater attention in future studies of economic transformation.

The coefficient on the time trend variable used to proxy the possible bias of technical change in agriculture relative to the rest of the economy presents particular difficulties. While this variable is statistically insignificant, there is widely believed to be such a bias in technical change at least in the poorer countries (Dowrick \& Gemmell, 1989). Further, the lack of significance of this variable maybe more indicative of multicollinearity between this and other trending variables than of a lack of bias. If this is the case, then exclusion of this relevant explanatory variable may result in bias in other coefficient estimates. When the measure for the potential bias of technical change is included, this effect is an important contributing factor to the overall decline in the share of agriculture in the economy. This factor alone contributes an estimated 49 per cent of the reduction in agriculture's share. Despite its apparent statistical insignificance, this variable is potentially of very great economic importance.

\section{Conclusions}

Four fundamental determinants of the ubiquitous decline have been identified in the role of agriculture as economies develop:

(1) demand side influences which lower the price of food relative to prices of all other goods;

(2) demand/supply forces which raise the price of non-traded goods relative to all traded goods;

(3) changes in factor endowments which can be expected to cause relatively labor intensive sectors to contract; and

(4) a possible bias in technical change against agriculture.

The two demand-side influences identified operate solely through relative commodity prices which have not been attempted to explain this study. Our attention is focused on the proximate determinants of agriculture's share: relative output prices; relative factor endowments; and bias in technical change.

Incorporation of dynamic adjustment terms based on an adjustment cost model resulted in smaller rather than larger estimates of the long run price response elasticity.

The preferred single equation estimators yielded small positive own-price supply elasticity at the sample mean and at most points in the sample, and quite sizeable estimates at the end of the sample. Small absolute values of the own price elasticity are not particularly surprising, since own price elasticities at the aggregate level would be expected to be substantially smaller than estimates at the individual commodity level. Nevertheless, the very small average own-price elasticity obtained may also reflect problems of aggregation, and the well known tendency for time series estimates of supply response parameters to be small in absolute value.

A decomposition of the total decline in the share of agriculture in GDP was undertaken using the preferred single-equation parameter estimates. Based on these estimates, the relative price effects which have received the most attention in the literature were found to be relatively minor influences. With both of the models used, the decline in the price of agricultural output relative to the price of manufactured output contributed around ten per cent of the measured decline in agriculture's share of GDP. The rise in the relative price of services contributed an additional 17 or 18 per cent. Moreover, the mechanism through which these relative price changes affected agriculture's measured share of GDP was almost entirely their effects on the value shares used in measuring GDP, rather than through agriculture's quantity response.

Changes in the economy's stocks of capital and labor, and a possible bias against agriculture in technical change were found to contribute over three quarters of the total decline in the share of agriculture in the Bihar economy. In one of the models used for the decomposition, a trend term for bias in technical change was retained despite an apparent lack of statistical significance because of the possibility that the standard error on this variable was overestimated. In this model, the bias in technical change was found to be an extremely important influence, accounting for almost half of the measured decline. When this variable was omitted because of its apparent lack of statistical significance, the importance of the capital and labor variables increased considerably, accounting for almost three quarters of the observed decline in the share of agriculture. Overall the tentative conclusion to emerge from this 
exploratory study was that, for Bihar at least, supply side influences such as capital accumulation and technical change may be the most important determinants of the decline in agriculture's share of GDP. Demand side factors operating through relative commodity prices, seem to be much less important. This conclusion has major implications for policies for economic development and structural change, and suggests need for reorientation of agriculture's role in economic development towards supply side influences of factor accumulation and technical change.

\section{References}

Alauddin, M. and Tisdel, C. (1989). The green revolution and labor absorption in Bangladesh agriculture, Contributed Paper to the Conference of Economists, University of Adelaide, July 10-13.

Anderson, G. and Blundell, R. (1982). Estimation and hypothesis testing in dynamic singular equation system. Econometrica, 50(4): 1559-71.

Anderson, G. and Blundell, R. (1983). Testing restrictions in a flexible dynamic demand system: an application to consumers' expenditure in Canada. Review of Economic Studies, 50: 397; 410.

Anderson, K. (1987). On why agriculture declines with economic growth. Agricultural Economics, 195-207.

Bale, M. and Lutz, E. (1981). Price distortions in agriculture: an international comparison. American Journal of Agricultural Economics, 63(1): 8-22.

Beggs, J. (1988). Diagnostic testing in applied econometrics. Economic Record, 64(185): 81-101.

Bewley, R. (1979). The direct estimation of the equilibrium response in a linear dynamic model. Economics Letters, 3 : 357-61.

Bewley, R. (1986). Allocation Models: Specification Estimation and Applications. Ballinger Cambridge Mass.

Bewley, R. and Elliott, G. (1989). The rejection of homogeneity in demand and supply analysis: an explanation and solution. Discussion Paper 82/2, School of Economic. University of New South Wales.

Binswanger. H. (1974). A microeconomic approach to induced innovation. Economic Journal, 940-58.

Booth, A. and Sundrum, R. (1985). Labor Absorption in Agriculture. Oxford University Press, Oxford.

Cavallo, D. and Mundlak, Y. (1982). Agriculture and economic growth in an open economy: the case of Argentina, Research Report No 36. International food Policy Research Institute, Washington, D.C.

Caves, R. and Jones, R. (1913). World Trade and Payments. Little. Brown and Company. Boston.

Chenery, H., Robinson, S., and Syrquin, M. (1986). Industrialization and Growth: A Comparative Study. Oxford University Press for the World Bank.

Debabrata, P. M., Pattanaik, S., John, J., and Bahera, H. (2016). Monetary Policy transmission in India: Do Global Spillover Matters? Reserve Bank of India occasional Papers. Vol. 37(1\&2).

Dickey, D. and Fuller, W. (1979). Distribution of estimators for autoregressive time series with a unit root. Journal of the American Statistical Association, 74(366): 427-31.

Diewert, W. E. (1974). Applications of duality theory in M. Intrilingator and D. Kendrick. Frontiers of Quantitative Economics, North-Holland, Amsterdam.

Diewert, W. E. and Morrison, C. J. (1988). "Export supply and import demand functions: a production theory approach" in R. Feenst (ed.), Empirical Methods for International Trade, MIT Press, London.

Diewert, W. E. and Wales, T. (1987). Flexible functional forms and global curvature conditions. Econometrica, 55(1): 45-68.

Dowrick, S. (1989). Sectoral change, catching up and slowing down: post-war economic growth revisited, Australian National University (mimeo.).

Dowrick, S. and Gemmell, N. (1989). Industrialization, catching up and economic growth, Australian National University (mimeo.).

Engle, R. and Granger, C. (1987). Co-integration and error correction: representation, estimation and testing'. Econometrica, 55(2): 251-76.

Engle, R., Granger, C., and Yoo, B. (1987). Forecasting and testing in integrated systems. Journal of Econometrics, 35: 
143-59.

Epstein, L. (1981). Duality theory and functional forms for dynamic factor demands. Review of Economic Studies, 48: 81-95.

Falvey, R. and Gemmell, N. (1989). "Explaining service price differences in international comparison”, Working Papers in Trade and Development 89/2, Department of Economics and National Centre for Development Studies. Research School of Pacific Studies, Australian National University.

Fei, J. and Ranis, G. (1964). Development of the Labor Surplus Economy. Irwin, Homewood, Ill.

Fisher, B. S. (1979). The demand for meat: an example of an incomplete commodity demand system. Australian Journal of Agricultural Economics, 2.1(3): 220-30.

Fuller, W. (1976). Introduction to Statistical Time Series. John Wiley, New York.

Gemmell, N. (1982). Economic development and structural change: the role of the service sector. Journal of Development Studies, 19(1): 37-66.

Goyal, A. and Agarwal, D. (2017). Monetary Transmission in India: Working of Price and Quantum Channels, Indira Gandhi Institute of Development Research working paper no. 17.

Gregory. A., Pagan, A., and Smith, G. (1989). Estimating Euler equations from linear quadratic models. Seminar paper presented in the Dept of Economic. RSSS, Australian National University.

Guilkcy, D. and Lovell, K. (1980). On the flexibility of the translog approximation. International Economic Review, 21(1): 137-47.

Harris, J. and Todaro, M. (1970). Migration, unemployment and development: a two-sector analysis. American Economic Review, 60(1): 126-62.

Hayani, Y. and Ruttan, V. (1985). Agricultural Development: An International Perspective. Johns Hopkins, Baltimore.

Johnson, M. and Pasour, E. (1981). An opportunity cost view of fixed asset theory. American Journal of Agricultural Economics, 63(1): 1-7.

Johnston, B. (1970). Agriculture and structural transformation in developing countries, a survey of research. Journal of Economic literature, 8: 369-404.

Johnston, B. and Mellor, J. (1961). The role of agriculture in economic development. American Economic Review, 5l(4): 566-92.

Jorgenson, D. W. (1961). The development of a dual economy. Economic Journal, 71: 309-34.

Jorgenson, D. W. (1988). Productivity and postwar economy growth. Journal of Economic Perspectives, 2(4): 2342.

Kohl, I. U. (1978). A gross national product function and the derived demand for imports and exports. Canadian Journal of Economics, XJ(2): 167-82.

Kreuger, A., Schiff, M., and Valdes, A. (1988). Agricultural incentives in developing countries: measuring the effed of sectoral and economy wide policies. World Bank Economic Review, 2(3): 255-71.

Lau, L. (1978). “Testing and imposing monotonicity convexity and quasi-convexity constraints”. In M. Fuss and D. Mc Faddends, Production Economics, Vol I, North Holland. Amsterdam.

Lewis, P., Matin, W., and Savage, C. (1988). Capital and investment in the rural economy. Quarterly Review of the Rural Economy, 10(1): 48-53.

Ministry of Statistics \& Program Implementation, India. (2019a). State-wise and Item-wise Value of Output from Agriculture, Forestry and Fishing.

Ministry of Statistics \& Program Implementation, India. (2019b). Annual Report of Periodic Labor Force Survey.

Mishra, P., Montial, P., and Sengupta, R. (2016). Monetary Transmission in Developing countries: Evidence from India IMF Working Papers No. 16/167.

Myint, H. T. (1975). “Agriculture and economic development in the open economy” in L. G. Reynolds (ed.), Agriculture in Economic Development, Yale University Press, New Haven, 327: 54.

Nakamura, S. (1986). “A flexible dynamic model of multiproduct technology for the West Germany Economy. Journal 
of Applied Econometrics, 1: 333-44.

Ranis, G. and Fei, J. (1961). A theory of economic development. “America” Economic Review, 51: 533-65.

Rao, M. (1986). Agriculture in recent development theory. Journal of Development Economics, 22: 41-86.

Reynolds, L. G. (1975). “Agriculture in development theory: an overview” in L.G. Reynolds (ed.), Agriculture in Development Theory, Yale University Press, New Haven, 1-24.

Rybczynsky, T. N. (1955). Factor endowments and relative commodity prices. Economica, 22(4).

Schultz, T. W. (1953). The Economic Organization of Agriculture. McGraw Hill, New York.

Schultz, T. W. (1964). Trans/arming Traditional Agriculture. Yale University Press, New Haven.

Sen, A. K. (1966). Peasants and dualism with and without surplus labor. Journal of Political Economy, 74: 425-50.

Sinha, J. K. and Sinha, A. K. (2020). Trend and Growth of Capital Stock in Bihar During 1980-2017. Journal of Humanities, Arts and Social Science, 2020, 4(1), 57-66.

Stock, J. (1987). Asymptotic properties of least squares estimates of cointegrating vectors. Econometrica, 55(5): 1035.56.

Summers, R. and Heston, A. (1987). A new set of international comparisons of real product and price levels: estimates for 130 countries. Review of Income and Wealth, 34: 1-25.

Sunil, J., Sankershan, S., and Pramod, K. (2017). Estimation of Gross Value Added from Major crops using Cost of cultivation Study Data. Journal of Income and Wealth, vol. 39.

Timmer, C. P. (1988). “The agricultural transformation” in. H. Chenery and T. N. Srinivasan (eds.), Handbook of Development Economics, Vol. 1, North Holland, Amsterdam: 275-31.

Tweeten, L. T. (1979). Foundations of Farm Policy, 2nd ed., University of Nebraska Press, Lincoln, Nebraska.

Vasavada, V. and Ball, V. E. (1988). Modeling dynamic adjustment in a multi-output framework, Staff Report AGES880205, Economic Research Service, USDA.

Wickens, M. and Breusch, T. (1988). Dynamic specification, the long-run and the estimation of transformed regression models. Economic Journal, 98: 189-205.

World Bank. (1982). World Development Report: 1982, Oxford University Press, New York. 